\title{
Cinematografia e conteúdos acadêmicos de Psicologia: fortalecendo conexões e reflexões
}

Cinematography and academic contents of Psychology: fortifying connections and reflections

Cinematografía y contenidos académicos de Psicología: fortaleciendo conexiones y reflexiones

Idonezia Collodel Benetti*

\begin{abstract}
Resumo
A transformação da produção artesanal em industrial só foi possível com a divisão do trabalho e a transformação do trabalhador total em executante de tarefas fragmentadas. Como resultado dessas transformações, muitas mudanças ocorreram nas grandes empresas; com a globalização, elas deixaram as corporações e o trabalhador em uma situação nada confortável, pois a competitividade tem lançado grandes desafios para ambos. Metodologicamente, esse trabalho baseou-se no estruturalismo de Lévi-Strauss e na análise sintática da narrativa de Greimas. Tem por objetivo aliar a revisão de alguns trabalhos acadêmicos ao filme "Em boa companhia” (2004) e mostrar que o olhar crítico, lançado pela cinematografia sobre as relações de trabalho no ambiente empresarial, pode ser um forte aliado do professor de Psicologia organizacional e do trabalho em temos de reflexão crítica.
\end{abstract}

Palavras-chave: Cinematografia. Psicologia. Trabalho. Reflexão crítica.

\begin{abstract}
The transition from manufactured production into production on a large scale has the objective of gains in productivity and the increasing of capital. Labor division and the conversion of the situation characterized by an "integral worker" to a new situation lead the workers to the execution of fragmented activities. Changes took place inside labor institutions that, altogether with the globalization, have caused instability inside companies, since the competitiveness has challenged both: employers and employees. Methodologically speaking, the present paper is based on Lévi-Strauss' structuralism and on Greimas' narrative analysis. It is also aimed at connecting the review of the literature of some academic writings with the film "In good Company" (2004), and show that the
\end{abstract}

Mestranda em Psicologia na Universidade Federal de Santa Catarina, professora no Centro Universitário Barriga-Verde, psicóloga, psicopedagoga. 
critical view brought by the cinematography on the labor relations might be a strong ally of the psychological organizational professor, in terms of critical reflections.

Keywords: Cinematography. Psychology. Work. Critical reflection.

\section{Resumen}

La transformación de la producción artesanal en industrial sólo fue posible con la división del trabajo y con la transformación del trabajador total en ejecutante de tareas fragmentadas. Como resultado, se produjo muchas transformaciones en las grandes empresas; con la globalización tanto las corporaciones como el trabajador se quedadron en la "cuerda floja", pues la competitividad presenta grandes desafíos a ambos. Metodológicamente, este trabajo se basa en el estructuralismo de LéviStrauss y en el análisis sintáctico de la narrativa de Greimas. Tiene como objetivo aliar la revisión de algunos trabajos académicos a la película "En buena compañía" (2004), y mostrar que la mirada crítica que trae la cinematografía sobre las relaciones de trabajo en ambiente empresarial, pude ser un fuerte aliado del profesor de psicología organizacional y del trabajo, en términos de reflexiones críticas.

Palabras clave: Cinematografía. Psicología. Trabajo. Reflexiones críticas.

\section{Considerações iniciais}

A passagem do modo de produção feudal para o capitalista acarretou profundas modificações, que foram acompanhadas de transformações nas formas de organização social, envolvendo diferentes dimensões: cultural, política, educacional e econômica. A prática do artesão, trabalhador do período feudal, era caracterizada como própria de um trabalhador total, o qual tinha o domínio da concretização de sua "arte", e o domínio da operacionalização dos instrumentos que lhe proporcionavam começar e finalizar sua "obra", seguindo todas as etapas do processo de trabalho (Thomaz Junior, 2011; McDonough, 2010). Ele era dono do tempo, do processo e da produção de seu trabalho, e a ele era permitido acompanhar não só o desdobramento do processo, mas também a satisfação de ver finalizada, saída de suas mãos, a "obra de arte" final.

A transformação da produção artesanal em manufatureira e, posteriormente, em industrial só foi possível com a divisão do trabalho e a transformação do trabalhador total em trabalhador parcial, executante de tarefas fragmentadas. 
Nesse percurso, o trabalhador foi sendo alienado do processo de produção como um todo e, com os avanços da mecanização industrial, também ficou alheio ao produto em si. Expropriado do conhecimento produzido pelo seu ofício, "O operário passou a realizar operações rotineiras que não exigiam qualquer destreza especial. Com isso, a produção capitalista se realizou em sua plenitude" (Alves, 1998, p. 39).

Dentro desse contexto, e para a proposta deste estudo, os textos científicos trazem várias sínteses encontradas na área da Administração e da Psicologia organizacional e do trabalho. O filme, por sua vez, traz a empresa como pano de fundo para as relações interpessoais vivenciadas ao longo da trama, que oferece um retrato sutil sobre as mudanças ocorridas nas relações laborais nas últimas décadas, oferecendo uma visão apropriada sobre o trabalho e suas transformações nas instituições modernas.

\section{Ficha técnica e resumo do filme}

O filme foi lançado nos Estados Unidos, em 2004, com o título "In good company", traduzido em português brasileiro por "Em boa companhia". Classificado como comédia, foi dirigido por Paul Weitz e protagonizado por Dan Foreman (Dennis Quaid), um executivo que ocupa o cargo de gerente de marketing na revista "Sports America". Ele tem uma vida confortável junto a sua família (esposa grávida e duas filhas adolescentes). Aos 51 anos de idade, vê seu emprego ameaçado pelo inexperiente jovem de 26 anos Carter Duryea (Topher Grace), quando este assume o cargo de Dan. Começa, então, o pesadelo desse chefe de família.

\section{Chão teórico}

Com o surto do desenvolvimento, criaram-se modelos de organização do trabalho, entre eles o fordismo e o taylorismo, com o objetivo de aumentar radicalmente a produção do que era feito. $\mathrm{O}$ termo fordismo é um conceito que tem como intuito caracterizar o modo de gestão e produção estabelecido por Henry Ford, tanto na idealização (projeto), concepção e qualificação dos produtos quanto nas esteiras da linha de montagem da Ford Motors Company: um modo de produção mecânico, fragmentado, ditado pela tecnologia, objetivando pôr fim ao não desperdício de tempo, proporcionando maior produtividade.

Visando, também, à maior produtividade e lucratividade, o engenheiro norte-americano F. W. Taylor desenvolve a metodologia conhecida como 
"organização científica do trabalho". Assim, o taylorismo teve como principal intenção eliminar os movimentos inúteis no processo de criação dos produtos, para maximizar a produção e os lucros (Cattani, 2002).

Em comum, podemos dizer que esses dois modos de produção tiram a autonomia do trabalhador frente ao processo de concepção e finalização dos produtos. A implantação da maquinaria, nesses dois sistemas de gestão, dispensa as capacidades intelectuais/subjetivas dos indivíduos que trabalham, transformando, assim, o operário em uma "engrenagem humana" acoplada à máquina. Além disso, ignora os efeitos da fadiga e os aspectos humanos, psicológicos e fisiológicos encapsulados no contexto e nas condiçôes de trabalho.

Com os avanços da tecnologia, um novo modelo de estruturação aparece: o toyotismo, modelo japonês, caracterizado pela automatização e gestão participativa. O trabalho em equipe é a grande estratégia usada pelo toyotismo para racionalizar o uso de mão de obra: a ordem é trabalhar com um efetivo mínimo.

Outra característica do modelo japonês é a do trabalho em "células", o que capacita os funcionários para o trabalho em outros setores da empresa, tornando-o versátil, podendo substituir colegas e (ou) acumular funções quando necessário. Diante dessa breve análise, pode-se afirmar que essas três formas de gestão concordam ao menos em um objetivo: o aumento da produtividade/lucratividade.

Vale ainda enfatizar que as modificações nos meios organizacionais não são apenas caracterizadas por transformações em sua infraestrutura. O próprio conhecimento se tornou uma via de mão dupla, ou seja, uma mercadoria e uma ferramenta de trabalho inovadora e capaz de inovação. Como resultado dessas transformações, houve uma reestruturação nas organizaçôes, visando a tornar a empresa menor, mais eficiente e mais rentável, em resposta à demanda econômica.

Assim, a competitividade vem de mãos dadas com a velocidade e a qualidade. Houve uma redução do tamanho das empresas, que ficaram mais "leves" e ganharam maior flexibilidade, além de reduzir a burocracia. Com o enxugamento, a estrutura aparece modificada e os números e as estatísticas devem ser mostrados como estando em franco crescimento e expansão, quando se trata de lucros; e, quando se trata de gastos, em vertiginoso declínio (Huws, 2007). 
Esses processos de mudança, juntamente com a globalização, deixaram tanto a empresa quanto o trabalhador em uma situação complicada, pois a competitividade lança desafios para ambos. A globalização (integração mundial das atividades de uma organização) caracteriza-se por imprimir mais intensidade e maior número de modificações, gerando a concorrência entre as empresas e produzindo, além da competitividade, a rivalidade no mercado de trabalho. É uma etapa mais avançada da internacionalização, em que os processos são organizados e atrelados à escala global, como se o mundo fosse um único país (Cretoiu, 2005).

$\mathrm{Na}$ opinião de Goulart e Guimarães (2002), o processo de globalização tem seu início com a internacionalização do capital no final do século XIX. Com o fim da Segunda Guerra Mundial, as empresas multinacionais começam a criar novas redes de relações. A revolução tecnológica influencia diretamente esse novo sistema, cobrando aperfeiçoamentos na área tecnológica. Percebe-se, então, que existe um entrelaçamento histórico entre globalização e tecnologia. Por essa razão, a "informática, as telecomunicações, a biotecnologia e as novas formas de energia" se caracterizam como fatores indispensáveis para o funcionamento das empresas (Goulart \& Guimarães, 2002, p. 21).

Porém o que, em primeira análise, parece encurtar as distâncias entre os povos do mundo torna esse distanciamento cada vez maior, isso porque os processos de internacionalização geram blocos regionais; países que se assemelham em produtividade reúnem-se, formando o que hoje conhecemos como blocos econômicos. Há abertura entre as fronteiras de países; uma empresa pode livremente se desenvolver e ter filiais distribuídas nos mais variados países e neles também desenvolver sua lucratividade nessas filiais.

Entretanto, existem aqueles que não conseguem se adaptar e nem têm acesso à era da informação e da globalização, o que acaba acentuando as diferenças entre ricos e pobres. Dados apresentados por Goulart e Guimarães (2002) indicam que, na relação população/PIB mundial da década de 1990, havia uma população de 5,3 bilhões de habitantes, em que se tinha um produto interno bruto (PIB) de 4.010 dólares por pessoa, produzidos anualmente. Esse valor significa que temos condições suficientes para sanar necessidades como educação, saneamento básico, saúde, segurança, etc. Porém o que acontece é o inverso: 75\% dos recursos ficam apenas com uma pequena parcela da população nos países ricos, o que representa apenas $15 \%$ da população mundial. Com isso, 3,2 bilhões de habitantes têm cerca de 350 dólares por ano e por pessoa. 
Observando tais dados, pode-se inferir que, nos países mais ricos, estão concentradas as maiores novidades e genialidades tecnológicas, bem como os seus maiores avanços e aparatos industriais, o que origina empresas poderosas e preparadas para competir no mercado mundial. No entanto, em países menos desenvolvidos, os aparatos tecnológicos são mais precários, pois a forma inacessível de tais equipamentos atrasa o desenvolvimento das indústrias, impedindo a lucratividade e atualização tecnológica. Podese afirmar que onde não há dinheiro para comprar não se pode produzir e, seguindo a mesma lógica, em não se podendo produzir, não se pode comprar.

Esse mesmo problema é encontrado em instituições de ensino. Escolas e faculdades de países ricos concentram tudo o que há de melhor e de mais tecnológico no momento, enquanto as de países menos desenvolvidos continuam sem apoio governamental e, portanto, não podem oferecer, na maioria das vezes, ensino de qualidade para sua clientela. Nessas condições, a dobradinha "ensino/qualidade" tornou-se uma mercadoria extremamente cara. Na condição de bem de consumo, a educação está restrita a poucos, porém a produtividade que exige qualidade exige, também, trabalhadores com qualificação. Essa qualificação, na visão de Goulart e Guimarães (2002, p. 28), exige do trabalhador "competências de leitura, interpretação de textos, raciocínio lógico-matemático e abstrato, etc.". Entretanto, enquanto o sistema "encolhe a mão", a população menos favorecida fica à deriva, tornando-se refém de políticas públicas deficitárias. Como o mundo globalizado exige qualificação e tecnologia de ponta, fica a seguinte questão: como estar qualificado para as exigências do mercado se é tão difícil conseguir subsídios e apoio para se preparar para ele?

\section{Procedimento de análise}

O filme "Em boa companhia" ("In good company", 2004) serve, aqui, de base para a abordagem dos seguintes conteúdos: a) revisão teórica de assuntos relacionados ao mundo do trabalho; b) estabelecimento dos pontos de contato entre as obras escritas, de cunho teórico, e a obra cinematográfica escolhida; e c) alguns aspectos de uma boa companhia no seu sentido mais abrangente (sentido da pessoa física e da jurídica).

Então, para alcançar os objetivos talhados para esse estudo, foram percorridas as seguintes etapas: a) assistir ao filme, anotando o nome dos personagens e as características relacionadas ao mundo corporativo; b) 
rever o filme e, em uma planilha com três colunas, separar e numerar algumas sequências - as quais são unidades narrativas determinadas por um corte/ recorte escolhido para análise (Passarelli, 2004) - registrando o resultado da observação dinâmica e concreta das categorias "ator", "ação" e a transcrição das "unidades narrativas" referente à ação recortada; c) acrescentar à planilha mais uma coluna à direita, para registrar observaçóes consideradas relevantes para a compreensão do significado das cenas selecionadas, tais como elementos como o cenário, o figurino, a trilha sonora, entre outros, fundamentais para a compreensão do conjunto que constitui um filme (Passareli, 2004); d) selecionar, entre as cenas registradas, as situaçôes que apresentam associações com os textos lidos; e) registrar as passagens textuais que melhor ilustram as cenas selecionadas, em nova coluna criada na planilha.

Para o levantamento da interface semântica de elementos relativos ao espaço laboral do mundo das corporaçôes modernas (presentes no textual escrito e no textual encenado) e para a análise contrastiva entre o trabalhador da Modernidade e o da Pós-modernidade, esse trabalho baseou-se no estruturalismo de Lévi-Strauss (1978) e a na análise sintática da narrativa (Greimas, 1976). O estruturalismo se concentra na estrutura das relaçôes entre dois ou mais signos, dando especial atenção a oposições binárias (novo/velho, liberdade/escravidão, permanente/passageiro, empregado/desempregado); além disso, permite identificar relações sem a preocupação/interesse em explicar como tudo isso se processa. A análise sintática da narrativa visa a dar mais visibilidade à lógica binário dicotômica, presente no texto, por meio da observação dinâmica e concreta dos protagonistas e suas ações. Por fim, a planilha gerada foi analisada à luz do referencial teórico depurado da revisão da literatura especializada na área da Psicologia organizacional; a análise realizada procurou destacar as sequências mais relevantes para a discussão dos resultados que emergiram $\mathrm{da}$ associação entre ciência psicológica e cinematografia.

\section{Discussão: filmografia, a ficção imitando e refletindo a realidade}

A palavra companhia, tanto na língua portuguesa quanto na inglesa (company), tem uma dimensão de significados bastante diversa, que se estende desde o ato de acompanhar, de estar em convivência (sinalizando, dessa maneira, estreita relação às pessoas físicas), até o mundo dos negócios, caracterizando sociedades organizacionais (comerciais e industriais). Partindo, então, desse cenário linguístico, esse estudo pretende analisar, 
em linhas gerais, não só a "companhia" inserida no mundo do mercado de trabalho globalizado, transnacionalizado e reestruturado dentro dos padrões da sociedade capitalista como também seu "duplo sentido", que aparece não somente no título do filme, mas que percorre toda a obra cinematográfica.

Nessa linha de pensamento, o levantamento semântico mostra o entrecruzamento de palavras e significados dos vários "ingredientes" que fazem parte da reestruturação produtiva industrial, que apresenta como cenário um mundo globalizado e tecnologia de ponta. Aqui são exibidos alguns elementos que aparecem explicitamente nos textos acadêmicos consultados e que se repetem na obra cinematográfica de Paul Weirtz (ora na fala dos personagens, ora no comportamento deles, pela atuação); algumas vezes, somente são percebidos pela sutiliza do contexto: angústia, capitalismo, competitividade, enxugamento, flexibilização, globalização, insegurança, internacionalização, produtividade, qualidade, reestruturação, sobrevivência, tecnologia, transnacionalização.

Dentro desse cenário, cabe a pergunta: o que pode ser realmente assustador para um homem de 51 anos, casado, pai de duas filhas, com um terceiro filho a caminho, tendo de pagar os estudos de uma das filhas na universidade? A resposta parece complexa, tendo em vista as mais diversas e inúmeras dificuldades que muitos seres humanos enfrentam no seu dia a dia. Porém, no filme "Em boa companhia", parece que a resposta para esse questionamento está na dissolução do trabalho e perda do status de gerente na empresa, na qual o cidadão trabalha há cerca de 20 anos, tendo de aceitar como chefe um rapaz com metade de sua idade e, portanto, com experiência profissional bastante enxuta.

$\mathrm{Na}$ verdade, essa falta de experiência é trazida para a tela não somente na fala do próprio personagem, mas também no seu comportamento nervoso na primeira reunião frente aos novos subordinados. Para acentuar esse panorama, Weitz coloca a inexperiência de Carter em contraste com seu poder quando, na saída da concessionária, o todo-poderoso, porém inexperiente, jovem bate seu valioso Porsche (símbolo máximo de poder) que, em suas mãos inexperientes, logo fica danificado. Entretanto, sendo ele um executivo do mundo globalizado, enfrenta a situação da falta de experiência diante do mundo dos negócios dizendo: "Eu não tenho experiência, mas eu aprendo rápido”.

É essa rapidez que caracteriza os tempos da globalização e da alta tecnologia; a falta dessa "agilidade" pós-moderna faz com que Dan fique à 
margem dos acontecimentos do mundo globalizado. Em uma reunião na empresa, na presença de todos os colegas e do diretor-geral da multinacional Globecom, ele diz um arsenal de frases que, do ponto de vista de um cidadão em sintonia com as mudanças e com os rumos da economia, jamais deveria ter, sequer, sido imaginadas: "O que o computador e a lucratividade no mundo financeiro têm a ver com esportes?”.

É, então, dentro desse cenário nada animador, que a estrada para a aposentadoria forçada e precoce parece surgir repentinamente, quando Dan Foreman é surpreendido pela avalanche aterradora do fenômeno "downsizing" (Chiavenato, 2000), que soterra os funcionários da empresa onde ele trabalha, visando àqueles que ocupam seus cargos de chefia há mais tempo. Essa técnica de enxugamento da estrutura organizacional, experienciada pelo diretor de marketing da revista "Sports America", visa a tornar os processos empresariais mais ágeis e competitivos, reduzindo a suposta hierarquia e, consequentemente, os custos administrativos.

Para isso, essa "ferramenta", comumente usada no mundo das organizações, elimina cargos e despesas (já que a ordem é diminuir custos e aumentar a produtividade sem perder a qualidade), incluindo o "staff" desde a alta gerência até supervisores e controladores. Na película, Weitz ilustra muito bem a atmosfera da globalização no contexto empresarial, trazendo o comentário de um dos funcionários da "Sports America": "Estão fazendo cortes nos gastos. Não querem um cara como você, que ganha bem".

Essa prática culmina na "horizontalização" da organização, que se afigura com "sobrepeso" ("quilinhos" extras configurados, também, na verticalidade do organograma). Porém essa técnica, metaforizada aqui como "lipoaspiração", apresenta "efeitos colaterais" visíveis. Na tentativa de tornar o organograma empresarial menos vertical, os colaboradores antigos entram em pânico, fazendo contagem regressiva na ansiedade de tentar adivinhar "quem será o próximo", já incluindo sua própria pessoa. A ansiedade, que é generalizada, atinge os funcionários remanescentes, que se sentem inseguros quanto ao fato de não saberem, exatamente, se estão trabalhado a contento ou se estão na lista que fará a empresa perder alguns "quilinhos" para ganhar fôlego, e tornar-se mais ágil, a fim de se adaptar e acompanhar as mudanças constantes do mercado. E os funcionários, que continuam em seus postos de trabalho, são forçados a passar por um

Horizontalização é o processo de envolvimento de terceiros: terceirização de produtos em parceria com outras empresas fornecedoras, especialistas nesses produtos. Essa conduta visa ao enxugamento de pessoal nas empresas. 
processo de "reeducação" que envolve "reaprender" a se relacionar com esse novo mercado que não para de se transformar.

Essas mudanças incluem, de acordo com Baumgarten (2006, p. 238), "transformação no processo de trabalho e introdução de tecnologia microeletrônica". Equivale dizer que, com a introdução e a adoção das novas tecnologias, menos pessoas executam um maior número de atividades, e os funcionários que permanecem na organização se veem forçados a aumentar a jornada de trabalho para poderem executar suas tarefas e evitar uma possível demissão; é a automação substituindo a mão de obra humana. Assim, inúmeras funções em diversos níveis entram em declínio, sendo consideradas obsoletas e, portanto, desnecessárias para a oxigenação e vitalidade empresarial. Ao acionar um simples botão, ou "clicar" um simples ícone, os processos virtuais se encarregam de controlar negócios e transaçôes, pulverizando, em nível mundial, cargos e tarefas que, no período fordista, operacionalizavam-se por ações repetitivas, frente ao olhar de um supervisor formatado para inspecionar e colocar o trabalhador "nos trilhos".

É dentro dessa perspectiva que muitos trabalhadores se tornam viciados em trabalho (workaholics) e, dessa maneira, sujeitam-se a vários procedimentos organizacionais, não questionando as técnicas administrativas aplicadas. Família, amigos, lazer são "artigos de luxo". O mais importante é pertencer à "família da empresa X" e vestir a sua camisa (da empresa), trabalhando 24 horas por dia, inclusive aos sábados, domingos e feriados.

Na obra de Paul Weitz, esse tipo de profissional é retratado como uma pessoa que exige de seus funcionários extrema dedicação, o que, muitas vezes, significa trabalhar nos fins de semana ou nos feriados, adiar as férias, fazer hora extra, cancelar uma viagem a passeio, etc. É o caso de Carter que, casado há apenas sete meses, enfrenta o divórcio, reconhecendo que o fracasso matrimonial se deveu ao fato de ele estar constantemente ausente, dedicar-se ao trabalho em demasia, não priorizar momentos (já que tempo é mercadoria; "tempo é dinheiro"), para se dedicar a si próprio, à sua esposa, ao seu lar.

Fora da grande tela, para muitos, o dia a dia não se configura de maneira diferente; $55 \%$ dos gerentes de empresas recebem reclamações constantes por não dedicarem tempo para o convívio familiar. Isso faz com que haja um alto nível de estresse entre os executivos, que têm de acumular funçôes, estar atualizados para conquistar mercados e serem competitivos dentro 
de um cenário global. A exigência se concentra na demanda por melhores resultados para a empresa, e alguns não suportam e sucumbem (Santos, 2008).

Entretanto, vale um olhar panorâmico e mais abrangente para o processo de globalização que leva o mercado de trabalho a reagir de maneira endógena e visceral, reestruturando-se internamente em movimentos bruscos e a construir um processo doentio de "queima de calorias", comprometendo a saúde empresarial ao promover desgosto, incerteza, insatisfação, insegurança, ansiedade, inimizades, falta de confiança entre colegas que, até então, consideravam-se praticamente como irmãos, etc. Ora, diante de um processo capitalista massacrante, que atinge o mercado de trabalho, fazendo com que as mudanças aconteçam com muita rapidez, o trabalhador, para segurar o emprego, tem de se manter em constante atualização, ser aberto e dinâmico, estar aprendendo coisas novas todos os dias; deve ser especialista em determinada área, mas não ficar restrito a uma determinada função, porque ela pode ser extinta de uma hora para outra. Assim, pode-se afirmar que não há lugar para coleguismo, amizade e companheirismo.

Nessa atmosfera hostil (Crowley, Tope, Chamberlain, \& Rodson, 2010), onde não existem contos de fadas, o que vale não é o apego fraternal entre as pessoas, mas sim assegurar a subsistência. Manter o atual emprego é o que importa; para que se alcancem objetivos ou simplesmente para que estes sejam mantidos, ignoram-se os conceitos e os valores da moral e da ética, pisando sobre o "cadáver" do companheiro de equipe. O próprio Carter, que protagonista do filme, interpreta um personagem que tem poucos vínculos com os negócios em si, tendo o trabalho como trampolim para novas oportunidades. Em uma conversa com seu superior hierárquico, manifesta-se dizendo: "Vou bater sem dó... não perdoarei... serei seu ninja assassino”.

Aqui, ainda cabem as palavras sábias de Hobbes (1984, p. 9) "Homo homini lupus", ou seja, o homem se tornando lobo do próprio homem. No filme, essa frase pode ser ilustrada na cena em que Paul Weitz, sabiamente, coloca dois peixes em um aquário e um destrói o outro. Vale lembrar que esses pequenos "animais de estimação" são as principais companhias do jovem protagonista. Sentindo a falta de um deles, Dan questiona Carter sobre a ausência do peixinho. Carter dá a seguinte resposta: "Buddy tinha um amigo. Ele o comeu”.

Esse ato de "comer" tem, também, como pano de fundo, a globalização e o poder dos seus tentáculos, que bate à porta, alcança a maçaneta e 
abraça, sem pedir licença, toda a família, aqui metaforizando a rede de empresas, fazendo-se refletir nos "staffs" e seus cargos. Assim, esse polvo gigantesco não oferece alternativas: alcança a todos, estendendo-se sobre os países subdesenvolvidos ou em vias de desenvolvimento, onde, por meio das grandes multinacionais e a troco da geração de empregos, sempre em moldes precários e explorando mão de obra barata, vão usufruindo de todas as benesses permitidas nesse contexto.

É importante enfatizar que a globalização promoveu uma revolução necessária para atender transformações na ordem política e econômica mundial das últimas décadas, nas tecnologias de informação. $O$ grande desenvolvimento científico e tecnológico, também chamado de Terceira Revolução Industrial ou Tecnológica foi, de acordo com Baumgarten (2002), fundamental para agilizar não só o comércio e as transações financeiras entre os países como também as transformações ocorridas no mercado de trabalho.

Vale salientar que a internet, com "nicho ecológico" na rede mundial de computadores, constitui-se na maior "ferramenta", que, por ironia, é virtual e, portanto, nada pesada como são conhecidas, classicamente, as ferramentas de trabalho, de integração entre as nações. É uma novidade tecnológica e, sem dúvida, um novo ramo de mercado: o virtual, fortalecendo a ideia de que "a relação entre globalização da economia e o desenvolvimento tecnológico é evidente (Huws, 2011)"; e, não apenas isso, mas também, fortalecendo as "grandes empresas, que puderam adquirir as inovações e se expandiram além das fronteiras de sua origem" (Goulart \& Guimarães, 2002, p. 31).

E, usando metáforas para a dicotomia velho/novo (sendo Dan Foreman o representante do velho, e Carter Dureya o símbolo do novo), poderíamos atribuir, ao primeiro, características da Modernidade (fordismo/taylorismo); já o segundo ilustraria o período da Pós-modernidade, enquanto cenário da contemporaneidade (modelo japonês, toyotismo) e seus desdobramentos, incrementado pelos eventos do "fenômeno" da globalização.

No filme, Dan é considerado "jurássico” e ultrapassado: "Ele [Carter] me chamou de Dinossauro". "Disse que eu preciso me atualizar.” Já Carter é colocado para o público atrelado à cultura oriental representando, quem sabe, o "boom" do avanço tecnológico (todas as vezes que está em um restaurante, seu pedido é sempre "sushi" ou "sashimi”).

E por que não colocar, dentro da ousadia do uso das metáforas, Dan como símbolo do período que antecede à globalização e Carter como 
ícone dos novos tempos, representando as mudanças ocorridas a partir da década de 1980 com a ascensão do taylorismo, a queda da cortina de ferro e o estabelecimento efetivo do mundo globalizado? Coerente com esse fluxo de pensamento, poderíamos então resumir o trabalhador moderno e o pós-moderno dentro do quadro a seguir:

\section{Quadro 1 - Modos de produção: contraste entre o trabalhador da Modernidade e da Pós-Modernidade}

\section{Dan: Modernidade}

Especializado em operacionalizar apenas uma atividade; fragmentação da função com tendência a uma desabilitação quase que total do trabalhador;

trabalha com produtos mais homogêneos (produção em série);

vive o cotidiano de uma empresa concentrada (uma ou poucas unidades) e estruturalmente verticalizada (organograma mais denso e "pesado"), estruturas mais complexas de organização, com grande número de trabalhadores nos diversos níveis hierárquicos;

desabituado a um planejamento flexível de produção (rígido quanto à capacidade de adaptação rápida às exigências do mercado);

\section{Carter: Pós-Modernidade}

Atento à flexibilidade dos processos de trabalho, dos mercados de trabalho, dos produtos e padrões de consumo;

capaz de ter autonomia, iniciativa, imaginação, criatividade, agilidade de raciocínio, dedicação;

tem habilidade para analisar, interpretar, criar, tomar decisões, corrigir instruções, trabalhar em equipe, comunicar-se (interatividade), e trabalhar em vários postos na empresa;

acompanha a evolução tecnológica e adapta-se facilmente não só a novas situações e a diferentes funções, mas também a um mundo em constante movimento e mudanças;

habituado à comunicação escrita, em vez da oral (predominando a impessoalidade e o formalismo nas relações); tem aptidão intelectual para dominar novas técnicas (é um trabalhador mais escolarizado e mais qualificado);

é polivalente, ágil, dedicado, multifacetado, multifuncional, tendo facilidade de treinamento e pensando sempre com o "cérebro" da empresa;

trabalhador mais mecanicista, centralizador e simplificador;

lento para acompanhar as mudanças socioculturais $\mathrm{e}$ econômicas; tem competência e capacidade para agir, intervir, decidir em momentos e situações que podem ser previsíveis ou não;

é capaz de trabalhar com estoque mínimo. não participa nas decisões da empresa, que despreza o saber intelectual da mão de obra que nela atua.

Fonte: elaborado para este artigo. 
O que significa, então, estar “em boa companhia?". Essa pergunta pode ter várias respostas, dependendo, obviamente, da teoria a ela associada para formular e fornecer a contrapartida. Desse modo, se olharmos pelo prisma da empresa globalizada, reconheceremos que, para "estar em boa companhia", é necessário que o funcionário seja um "colaborador" da empresa, formando com ela um "espírito de corpo", tendo "flexibilização" como palavra-chave do seu cotidiano. Além disso, precisa estar disponível para horas extras de trabalho, já que as "boas companhias" têm seus quadros enxutos (estruturados com base em um número mínimo de trabalhadores).

Indo um pouco mais além, estar "em boa companhia" também significa estar atento às novas exigências e competência impostas aos trabalhadores. Entre elas, criatividade, sensibilidade e visão empresarial: julgar, ponderar, avaliar, achar solução, discutir e decidir de forma conveniente e adequada. Para isso é preciso "saber", como conhecimento, "saber fazer", como prática desse conhecimento, que envolve também habilidade e percepção, e "saber conviver", como relacionamento, uma vez que interatividade e comunicação fazem parte do dia a dia da "boa companhia".

Além disso, o funcionário que deseja continuar "em boa companhia" precisa estar ciente de que um diploma de uma universidade já não é o referencial mais importante, já que se tornou um ingrediente básico e não mais um diferencial. De acordo com o Jornal Zero Hora ( $1^{\circ}$ de maio de 2005 , p. 4), "Nos últimos 10 anos, o número de pessoas com diploma em curso superior aumentou $119 \%$. Ser graduado se tornou básico, não diferente. E isso exige buscar outros diferenciais".

Assim, além do certificado de graduação, exigido e necessário, existem outros diferenciais que a "boa companhia" faz questão de priorizar. Um deles é o aspecto cognitivo (a participação intelectual do trabalhador é valorizada). É nessa dinâmica que a escolarização se torna mais um item do currículo do colaborador; é o impacto das inovações tecnológicas forçando a elevação do nível de qualificação do funcionário, mostrando um cenário que prioriza a demanda por profissionais qualificados, que descarta e (ou) diminui a mão de obra semiqualificada em todas as áreas empresariais.

Assim, além de levar o profissional à exaustão física, com a polivalência funcional, a pluralidade de tarefas e o aumento de carga horária, a empresa também se apropria do saber intelectual do proletário, e quem não se adapta ao perfil exigido é descartado. É importante salientar, entretanto, que, às vezes, mesmo se esforçando e se preparando para enfrentar as novas exigências do mercado, muitos presenciam e vivenciam ocupações do tipo "meio período", 
do emprego temporário sem vínculo, ou o desemprego real. Para evitar o desconforto de ser mais um trabalhador desempregado ou para não enfrentar a informalidade do mercado, "estar em boa companhia" significa, entre outras coisas, deixar-se sugar física e intelectualmente. É a lógica do capital capturando a subjetividade do proletariado "assujeitado":2 o poder das empresas, que acaba atacando o sujeito em todos os seus flancos.

Nesse novo sistema, estar "em boa companhia" significa, também, ver-se como uma extensão da empresa, mesmo nos feriados e finais de semana, ao procurar integrar-se ao time de futebol dos funcionários ou participar dos encontros tão em voga, chamados de "happy hour", no final do expediente, em companhia do chefe e dos colegas de equipe; ou, então, fazendo parte da "família da empresa", levando sua própria família, também um apenso da organização da qual faz parte, nas festas promovidas pela instituição empresarial. E, assim, o funcionário dos tempos globalizados é um trabalhador que se mantém 24 horas em contato com seu "locus laboral" e (ou) em companhia dos seus colegas de trabalho, tanto para o lazer quanto para atividades relacionadas às suas tarefas como trabalhador. Nessas condiçõos, ele realmente "veste a camisa da empresa". Porém tudo isso deixa transparecer que estar "em boa companhia" é, antes de tudo, priorizar e salvaguardar a sobrevivência.

E, dentro desse cenário onde o "homem é o lobo do homem", a boa companhia, no sentido de companheirismo, já não é tão "boa" e confiável; alegando questôes de sobrevivência, a qualquer momento, aquele que sempre foi considerado um amigo sendo, portanto, uma boa companhia, pode ser aquele que, de repente, pode "puxar o tapete" e deixar o colega "sem chão".

Pode-se, então, afirmar que é doloroso e deprimente admitir que, nesse mundo contraditório de relações "humanas" pautadas na "selvageria" (contraste humano/selvagem), construído em bases capitalistas de concorrência, competitividade e desumanidade, onde, de acordo com dados trazidos por Goulart e Guimarães (2002), 3,2 bilhões de pessoas vivem com menos de um dólar por dia, cabe bem o provérbio popular: "Quem pode mais, chora menos". Vale enfatizar que os atuais modos de produção capitalista, com sua nova gestão da força de trabalho, continuam favorecendo a lógica do capital (Antunes, 2007; Beaud \& Pialoux, 2009),

\footnotetext{
Os analistas franceses defendem a ideia de que um sujeito, ao passar de um ambiente para outro, assume os discursos institucionais possíveis, de acordo com seu trânsito pelos vários e diferentes ambientes. Esse processo de adaptação discursiva é identificado como assujeitamento. Assim, o sujeito, de acordo com a perspectiva estruturalista, pode ser assujeitado pela estrutura social, pela estrutura do inconsciente e pela estrutura linguística (Pêcheux, 1990).
} 
atingindo e aproveitando o cidadão na sua integralidade física, emocional, intelectual e social; o indivíduo pode ser útil no trabalho forçado e também contribuindo com seu raciocínio e inteligência.

Ao contrário dos modelos taylorista e fordista, só a força do trabalho muscular, repetitivo, cronometrado, limitante e livre de iniciativas já não é suficiente, uma vez que a produção e os lucros podem ser ampliados com a exploração da imaginação, da criatividade, da capacidade de atuação em equipes de controle e da capacidade de cooperação; tudo isso atrelado ao toyotismo que, vinculado à Terceira Revolução Industrial e à globalização, faz nascer não só um novo conceito em estruturação produtiva, mas também um novo tipo de homem (que se confunde com o homem da Pós-modernidade): de um lado do ringue, está o homem flexível, polivalente, plurifuncional, comunicativo, competitivo, cooperador, participativo, porém frio, calculista, explorador, cruel. Já, do outro lado do ringue, está o explorado, o desempregado, o excluído, o não especializado que, muitas vezes, nessa condição, acaba se tornando (e sendo contabilizado pelos números da estatística) como um pária social (Lessa, 2007).

\section{Considerações finais}

A sétima arte, bem como outras formas de expressão artísticas, para além de serem entretenimento e espetáculo, atraindo e prendendo o olhar, são veículos da cultura, dos problemas e das ideias que pautam uma determinada época. Portanto, também trazem, encapsulados em seu conteúdo, a representação de crenças e valores culturais, sociais e ideológicos de uma sociedade e de uma geração, embutidos na cultura de quem produz e consome os conteúdos das películas cinematográficas.

Esses fenômenos atuam conjugando espaço e tempo (passado, presente e futuro, em transformação - às vezes, ocorrendo num processo simultâneo), locação e deslocamento, etc., expressos não somente em palavras, mas também na paisagem, na arquitetura, no figurino, nos gestos, nos ambientes e sua decoração. Dessa maneira, os filmes traduzem conceitos, revelam novas formas de apresentação da realidade e, como um veículo de comunicação de massa, podem modificar ideologias.

Então, tendo em vista as possibilidades de reflexão geradas pela análise dessa obra de arte, foi elaborado este estudo, indicando que o diálogo entre a cinematografia e conteúdos de Psicologia é possível e recomendável, se levado em consideração que esse recurso pode, entre muitas coisas, ser útil para: a) enriquecer o olhar do público assistente (professor/alunos) sobre 
a educação acadêmica, sinalizando que esse tipo de tecnologia pode ser objeto de pesquisa e análise; b) proporcionar momento crítico e reflexivo de aprofundamento de conteúdo; c) facilitar a aprendizagem de conteúdos, instaurando uma situação que favorece uma visão prática da aprendizagem; d) estimular o aluno a criar e buscar novos conhecimentos, apropriando-se das novas tecnologias; e) fomentar o interesse da plateia e estimular uma postura crítica frente ao conteúdo assistido; f) relacionar o conteúdo de textos científicos com o conteúdo cinematográfico, construindo uma ponte que aproxima o cotidiano (senso comum) e questóes relativas à ciência; g) discutir conceitos teóricos sobre a Modernidade nas corporações e as novas relaçôes de trabalho ali produzidas; h) contribuir para a significação dos conceitos trazidos pelos textos científicos; i) auxiliar na construção do conhecimento e de cada aluno como sujeito histórico; j) demonstrar que é possível contar com a tecnologia educacional nas práticas pedagógicas e estimular reflexões e novas pesquisas sobre essas práticas, que venham a contribuir para as exigências curriculares da disciplina de Psicologia organizacional e do trabalho, no curso de Administração de Empresas.

Vale realçar que fazer docência em Psicologia, como em qualquer outra área, requer uma postura de evitação da comodidade que leva à perpetuação e à reprodução de práticas tradicionais, as quais tendem a repetir açôes que contrariam e anulam o espaço da reflexão e da crítica, como ações que visam a ancorar a compreensão da realidade (Lima \& Sales, 2002). Então, o uso de recursos motivadores e estimuladores do diálogo pedagógico, que priorize a reflexão e a atividade do senso crítico, devem ser buscados, a fim de dar melhor qualidade ao trabalho realizado em sala de aula.

A práxis da Psicologia organizacional significa trabalho vivo, um movimento dialético entre ação e reflexão em um espaço docente que permita a constante problematização de assuntos e tarefas emergentes da realidade, e o sujeito seja visto em sua multidimensionalidade, tendo em vista que ele é um ser intelectual, afetivo social, cultural, biológico, etc., convivendo em um cenário de constantes mudanças.

Concluindo, a sala de aula deve ser palco para o crescimento e o desenvolvimento do indivíduo em sua totalidade. Para tanto, é vital que seja levado em consideração o desenvolvimento tecnológico e a influência que a mídia exerce no dia a dia do mundo globalizado, para que sejam utilizados os bons recursos que se apresentam na atualidade. Já que a mídia e a produção cultural industrializada bombardeiam o cotidiano, por que não tirar proveito e usar a obra de arte cinematográfica para possibilitar (re)leituras das teorias da Psicologia organizacional e do trabalho, favorecendo a articulação entre os 
textos acadêmicos e a cinematografia, na vivência do cotidiano acadêmico? Como signos mediadores - da mediação no sentido entendido por Vygotsky (1999) - com potencial para o desenvolvimento crítico-reflexivo da audiência alvo, o cinema na sala de aula não pode ser usado somente como um espetáculo, visando à diversão e ao entretenimento, ou como um recurso de segunda ordem.

Nesse viés, destaca-se a importância de privilegiar a aplicação de práticas pedagógicas que contribuam para o processo de aprendizagem tanto técnico quanto social, com vistas a uma formação profissional ética, competente e comprometida com o entorno no qual os indivíduos estão inseridos. Nesse sentido, se "A arte imita a vida", a narrativa fílmica de várias produçōes cinematográficas propicia discutir o comportamento humano e seus desdobramentos, por meio das "sugestôes/provocações" projetadas na tela.

\section{Referências}

Alves, L. (1998). A produção da escola pública contemporânea. Campinas: Unicamp.

Antunes, R. (2007). Dimensões da precarização estrutural do trabalho. In: G. Druck \& T. Franco (Org.). Perda da razão social do trabalho. (pp. 13-22). São Paulo: Boitempo.

Baumgarten, M. (2006). Reestruturação produtiva e industrial. In: A. Cattani \& L. Holzmann (Org.). Dicionário trabalho e tecnologia. (pp. 237-239.). Porto Alegre: Editora da UFRGS.

Beaud, S. \& Pialoux, M. (2009). Retorno à condição operária. São Paulo: Boitempo.

Cattani, A. D. (2002). Taylorismo. In: A. D. Cattani (Org.). Dicionário crítico sobre trabalho e tecnologia. (pp. 247-249). Petrópolis: Vozes.

Chiavenato, I. (2000). Introdução à teoria geral da administração. São Paulo: Campus.

Cretoiu, S. L. (2007). Internacionalização de pequenas e médias empresas. In: Almeida, André (Org.). Internacionalização de empresas brasileiras: perspectivas e riscos. Rio de Janeiro: Elsevier. 
Crowley, M., Tope, D., Chamberlain, L. J. \& Rodson, R. (2010). Neotaylorism at work: occupational change in the post-fordist era. Social Problems, 57 (3), 421-447.

Greimas, A. J. (1976). Semântica estrutural. São Paulo: Cultrix; Edusp.

Goulart, I. \& Guimarães, R. F. (2002). Cenários contemporâneos do mundo do trabalho. In: I. Goulart (Org.). Psicologia organizacional do trabalho: teoria, pesquisa e temas correlatos. (pp. 17-36). São Paulo: Casa do Psicólogo.

Hobbes, T. (1984). Leviatã ou matéria, forma e poder de um Estado eclesiástico e civil. São Paulo: Abril.

Huws, U. (2007). The spark in the engine: creative workers in a global economy. Work organization labor and globalization, 1, 1-12.

Huws, U. (2011). A construção de um cibertariado? Trabalho virtual num mundo real. In: R. Antunes \& R. Braga (Org.). Infoproletários: degradação real do trabalho virtual. (pp. 37-58). São Paulo: Boitempo.

Lessa, S. (2007). Trabalho e proletariado no capitalismo contemporâneo. São Paulo: Cortez.

Lévi-Strauss, C. (1978). Myth and meaning. London: Routledge and Kegan Paul. Lima, M. S. L. \& Sales (2002). Aprendiz da prática docente: a didática no exercício do magistério. Fortaleza: Demócrito Rocha.

McDonough, T. (2010). The state of the art of social structure of accumulation theory. In: T. McDonough, M. Reich \& D. M. Kotz (Ed.). Understanding contemporary capitalism and its crises: social structure of accumulation theory for the twenty-first century. (pp. 38-29). New York: Cambridge University Press.

Passarelli, C. A. (2004). Imagens em diálogo: filmes que marcaram nossas vidas. In: M. J. Spink (Org.). Práticas discursivas e produção de sentidos no cotidiano. (pp. 273-283). São Paulo: Cortez.

Pêcheux, M. (1990). Discurso: estrutura ou acontecimento. Campinas: Pontes. Santos, M. (2008). Por uma outra globalização: do pensamento único à consciência universal. Rio de Janeiro: Record.

Thomaz Júnior, A. (2011). Intemperismo do trabalho e as disputas territoriais contemporâneas. Revista da Anpege, 7, 307-329.

Vygotsky, L. S. (1999). Pensamento e linguagem. Rio de Janeiro: Martins Fontes. 